J. Nepal Chem. Soc., vol. 30, 2012

\title{
Synthesis of Geopolymer from Inorganic Construction Waste
}

\author{
Arbind Pathak and Vinay Kumar Jha* \\ Central Department of Chemistry, Tribhuvan University, Kirtipur, Kathmandu, Nepal \\ E-mail: vinayj2@yahoo.com
}

\begin{abstract}
Recently, the demolition of old houses and the construction of new buildings in Kathmandu valley are in the peak which in turn generates a huge amount of construction waste. There are two major types of construction wastes which are burden for disposal namely cement-sand-waste (CSW) and the coal fly ash (CFA). These construction wastes are rich source of alumino-silicate and thus used as raw material for the synthesis of geopolymer in this study. Geopolymers have been synthesized from CSW and CFA using $\mathrm{NaOH}-\mathrm{KOH}$ and $\mathrm{Na}_{2} \mathrm{SiO}_{3}$ as activators. Some parameters like alkali concentration, amount of $\mathrm{Na}_{2} \mathrm{SiO}_{3}$ and curing time have been varied in order to improve the quality of geopolymeric product. The geopolymerization process has been carried out using 3-8M KOH/NaOH solutions, $\mathrm{Na}_{2} \mathrm{SiO}_{3}$ to $\mathrm{CFA}$ and CSW mass ratio of 0.25-2.00 and curing time variation from 5-28 days. The curing temperature was fixed at $40^{\circ} \mathrm{C}$ in all the cases. $6 \mathrm{M} \mathrm{NaOH}$ and $7 \mathrm{M} \mathrm{KOH}$ solutions were found appropriate alkali concentrations while the ratio of sodium silicate to CSW and CFA of 0.5 and 1.75 respectively were found suitable mass ratio for the process of geopolymer synthesis. The maximum compressive strength of only $7.3 \mathrm{MPa}$ after 15 days curing time with CSW raw material was achieved while with CFA, the compressive strength was found to be $41.9 \mathrm{MPa}$ with increasing the curing time up to 28 days.
\end{abstract}

Keywords: Cement-sand-waste, Coal fly ash, Compressive strength, Curing time, Geopolymer.

\section{Introduction}

Geopolymers are a new fire-, blast- and acid-resistant group of building materials. They are ceramiclike, inorganic polymers produced at low temperatures and have the potential to transform the building products industry. Victor Glukhovsky was the first who assumed that, since the geological process of transformations of some volcanic rocks at low temperatures and pressure; it might be modeled and carried out in cementitious systems. In 1972, Davidovits named 'geopolymers' the tri-dimensional aluminosilicates that are formed at low temperature and short time by naturally occurring alumino-silicates ${ }^{1}$.

The cost of using geopolymer-based building materials is similar to existing materials but these have greater technical and environmental benefits over the conventional cement type materials. These materials can help to cut back on damage done through industrial spills, improve long term performance, reduce capital or maintenance costs and further help to lower insurance costs. Besides these, geopolymer technology has the potential to reduce emission of carbon dioxide by $80 \%$ because high-temperature calcining is not needed while for every one tone of cement manufacturing, one tone of carbon dioxide is produced. Several types of waste product like fly ash, sludge, slag, construction waste and zeolitic tuffs can be utilized for the production of geopolymers.

Despite global economic melting down the construction of new buildings and demolition of old houses are in peak here in Kathmandu valley and other urban areas of the country. This particular

${ }^{*}$ Corresponding author 
behaviour has generated severe problem for the disposal of construction waste while in order to fulfill the demand, a huge amount of cement is produced every day in our country. In order to produce a ton of cement a similar amount of $\mathrm{CO}_{2}$ gas is emitted in the atmosphere.

The construction waste generally consists of cement, sand, brick, coal fly ash, etc. These construction wastes can be a good source of alumino-silicate material. Cement and sand consist a large proportion of aluminosilicate. The quality of a brick depends principally upon the kind of clay used. The material generally employed for making common bricks consists of sandy clay or alumino-silicate, and small quantities of lime, magnesia and iron oxide ${ }^{2}$. CFA is one of the residues generated in the combustion of coal. It typically comprises fine and powdery particles that are predominantly spherical, solid or hollow and mostly amorphous (glassy) materials. The chemical properties of CFA are greatly influenced by the chemical content of the coal burned. This alumino-silicate is the starting raw material for geopolymer production.

The industrial production of cement has two major drawbacks. The first one is the increase in environmental pollution and global warming as the manufacture of Portland cement produces large amounts of $\mathrm{CO}_{2}$ and the second one is the high energy consumption during the manufacture of cement as it involves very high temperature (about $1600^{\circ} \mathrm{C}$ ). Thus we are facing three severe problems; one associated with the huge amount of CFA waste, the second one is the atmospheric pollution and third one is the high consumption of energy. Hence, if it is possible to prepare geopolymers of reasonable compressive strength with CFA waste at ambient temperature, it can become a suitable alternative for minimizing the waste as well as for reducing the atmospheric pollution and energy consumption.

The geopolymer synthesized from metakaolin was cured at $65^{\circ} \mathrm{C}$ for $10 \mathrm{hrs}$. The maximum compressive strength of the sample was observed to be $35 \mathrm{MPa}$ in 35 days $^{3}$. A report on the effect of alkali and $\mathrm{Si} / \mathrm{Al}$ ratio on the development of mechanical properties of metakaolin- based geopolymer showed that the minimal change in the compressive strength of specimens was generally observed in specimens of different types of alkali in between 7 and 28 days of ageing. However, mixed alkali specimens with high $\mathrm{Al} / \mathrm{Si}$ ratio exhibited significant increase in strength and pure alkali specimens displayed decreased strength ${ }^{4}$. The blast furnace slag-metakaolin based geopolymers had shown that geopolymer containing $50 \%$ slag and synthesized at steam curing $\left(80^{\circ} \mathrm{C}\right.$ for $8 \mathrm{hrs}$.) exhibits high compressive strength of $75.2 \mathrm{MPa}^{5}$. The geopolymers synthesized from coal combustion fly ashes having glass content higher than $90 \%$ achieved the compressive strength about $60 \mathrm{MPa}$. Such geopolymers were synthesized using $12 \mathrm{M} \mathrm{NaOH}$ and by curing at $80^{\circ} \mathrm{C}$ for $48 \mathrm{hrs}^{6}$.

The influence of calcium compounds on the mechanical properties of fly ash geopolymer was studied and found that the calcium compounds improved the mechanical strength of samples cured at ambient temperature while on increasing the curing temperature at $70^{\circ} \mathrm{C}$ the compressive strength of samples were decreased ${ }^{7}$.

Geopolymer mortars of compressive strength 24-58 MPa were synthesized from lignite bottom ash with mean particle size of $15.7 \mu \mathrm{m}$ using liquid alkaline/ash ratio of $0.429-0.709$, the sodium silicate to $\mathrm{NaOH}$ ratio of $0.67-1.5$ and $7.5-12.5 \mathrm{M}^{8}$. Geopolymers from mechanochemically treated clinoptilolite were synthesized using $\mathrm{NaOH}$ and sodium silicate solutions which showed increasing compressive strength up to around $25 \mathrm{MPa}$ with increasing curing time ${ }^{9}$.

Thus, the major aim of the present study is to utilize various types of construction wastes for the synthesis of geopolymer with comparable crushing strength like ordinary cement materials without using any high temperature heat treatment and thereby to reduce the $\mathrm{CO}_{2}$ emission in atmosphere and save the energy consumption. 


\section{Experimental Methods}

\section{Sample Preparations}

The coal fly ash (CFA) used in this study was obtained from Kirtipur, Kathmandu. The CFA was ground manually by using mortar and pestle to obtain in fine powder form. The powder was further modified wet-milling by using iron balls ( $2 \mathrm{~mm}$ diameter) and distilled water in a plastic bottle and placed for rotating in self-assembled machine at room temperature.

The cement-sand-waste (CSW) used in this study was obtained from demolished part of Central Library, Tribhuvan University, Kirtipur, Kathmandu. The CSW was ground manually by using Khal, and mortar-pestle to obtain in fine powder form. The powder was further modified by wet-milling with using iron balls ( $2 \mathrm{~mm}$ diameter) and distilled water in a plastic bottle and placed for rotating in self-assembled machine at room temperature.

The solid sample was separated from solution by filtration and washed with distilled water for several times and then dried in oven (N6c, Philip Harris, England) at $80^{\circ} \mathrm{C}$ for overnight.

\section{Preparation of CSW/CFA Based Geopolymer}

To prepare CFA and CSW based geopolymer, several parameters such as $\mathrm{NaOH} / \mathrm{KOH}$ concentration, amount of sodium silicate and curing time were taken into account.

\section{Variation of $\mathrm{KOH}$ concentration}

In first case, the dried CSW and CFA powder sample was blended manually for 2 minutes with 3-8 $\mathrm{M} \mathrm{NaOH}$ and $\mathrm{KOH}$ solution separately using mortar and pestle. The blended mixtures were separately placed in cuboidal plastic moulds (length $\times$ breadth $\times$ height: $2.6 \mathrm{~cm} \times 2.6 \mathrm{~cm} \times 1.0 \mathrm{~cm}$ ), air bubbles were removed, sealed with thin plastic films and allowed to cure for 4 days in oven at $40^{\circ} \mathrm{C}$.

\section{Variation of amount of sodium silicate}

In second case, CSW and CFA powder was blended manually using mortar and pestle with the varying amount of $\mathrm{Na}_{2} \mathrm{SiO}_{3}$ while the concentration of $\mathrm{NaOH}$ and $\mathrm{KOH}$ solution was fixed. The blended mixtures were separately placed in cuboidal plastic moulds, sealed with thin plastic films and allowed to cure for 4 days in oven at $40^{\circ} \mathrm{C}$.

\section{Variation of curing time}

In third case, $\mathrm{Na}_{2} \mathrm{SiO}_{3}$ to construction waste of selected mass ratio was blended manually with the selected concentration of $\mathrm{NaOH} / \mathrm{KOH}$ solution using mortar and pestle. The blended mixtures were separately placed in cuboidal plastic moulds, sealed with thin plastic films and allowed to cure for 6-28 days in oven at $40^{\circ} \mathrm{C}$.

After curing, all the samples were demoulded and cut into finite sizes. The area of each piece of sample was measured prior to the strength measurement. In this step, the variation of the compressive strength with curing time was performed and hence the optimum compressive strength was achieved with 28 days of curing time at $40^{\circ} \mathrm{C}$.

The compressive strength of the samples was measured using MARUTO testing machine (s56A, Japan) available at National Academy of Science and Technology (NAST), Khumaltar, Lalitpur. The raw sample and fragments from the crushing tests of few characteristic samples were powdered and examined by X-ray diffraction (Bruker, D8 Advance, Germany). 


\section{Results and Discussion}

Characterization of construction wastes

The XRD pattern of CFA and CSW are shown in Fig. 1. CFA (a) and CSW (b) contain mostly amorphous glassy material and consist of a peak cantered on $\sim 26.6^{\circ}$ of $2 \theta$ angle. The presence of the sharp peaks at $26.6^{\circ}$ and $27.5^{\circ}$ of $2 \theta$ angle were due to the presence of quartz and/or mullite and silica $\left(\mathrm{SiO}_{2}\right)$ phases.

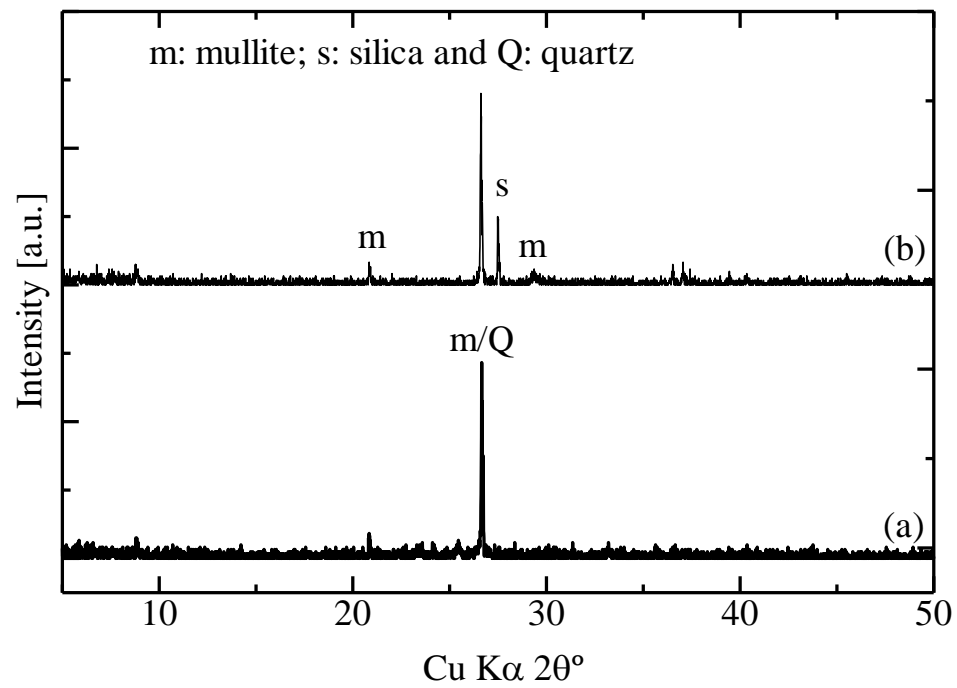

Figure 1: XRD patterns of (a) coal fly ash (CFA) and (b) cement-sand-waste (CSW).

\section{Compressive strength with alkali concentration variation}

In order for the selection of appropriate concentration of alkali for the synthesis of geopolymer from various types of construction wastes the alkali concentration was varied from 3 to $8 \mathrm{M}$. The change in compressive strength of products obtained from concentration wastes as a function of alkali concentration has shown in Fig. 2.

The compressive strength was found initially increased attaining the highest with 5,6 and $7 \mathrm{M}$ alkali concentrations in cases of $\mathrm{CSW}-\mathrm{NaOH}, \mathrm{CFA}-\mathrm{NaOH}$ and CFA-KOH respectively.

The increase in the compressive strength with increasing alkali concentration was due to the fact that higher amount of $\mathrm{OH}$ - ions facilitate the dissolution of silicate and aluminate species and thus promote polymerization $^{1}$. But under very high alkaline condition the connectivity of silicon anion may be reduced which causes alumino-silicate gel to precipitate at early stage resulting in poor polymerization i.e. $\mathrm{NaOH}$ or $\mathrm{KOH}$ molecule is incorporated between two geopolymer precursors which break the silicon anion connectivity thus preventing polymerization ${ }^{10}$. Further, the excess $\mathrm{NaOH}$ forms potassium carbonate by atmospheric carbon ${ }^{11}$.

\section{$\mathrm{Na}_{2} \mathrm{SiO}_{3}$ to construction wastes mass ratio and compressive strength}

The compressive strength of geopolymer products with the variation of the mass ratio of $\mathrm{Na}_{2} \mathrm{SiO}_{3}$ : construction waste while the alkali concentrations were set constant (For CSW- 5M NaOH and for CFA$6 \mathrm{M} \mathrm{NaOH}$ and $7 \mathrm{M} \mathrm{KOH}$ ) is shown in Fig. 3. 


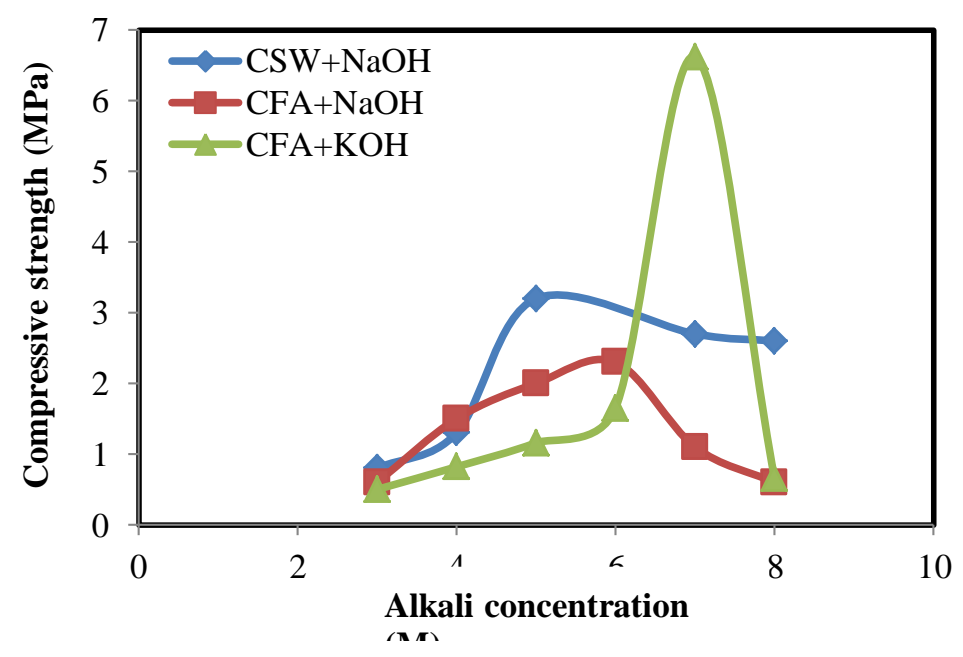

Figure 2: Variation of compressive strength of product as a function of alkali concentration.

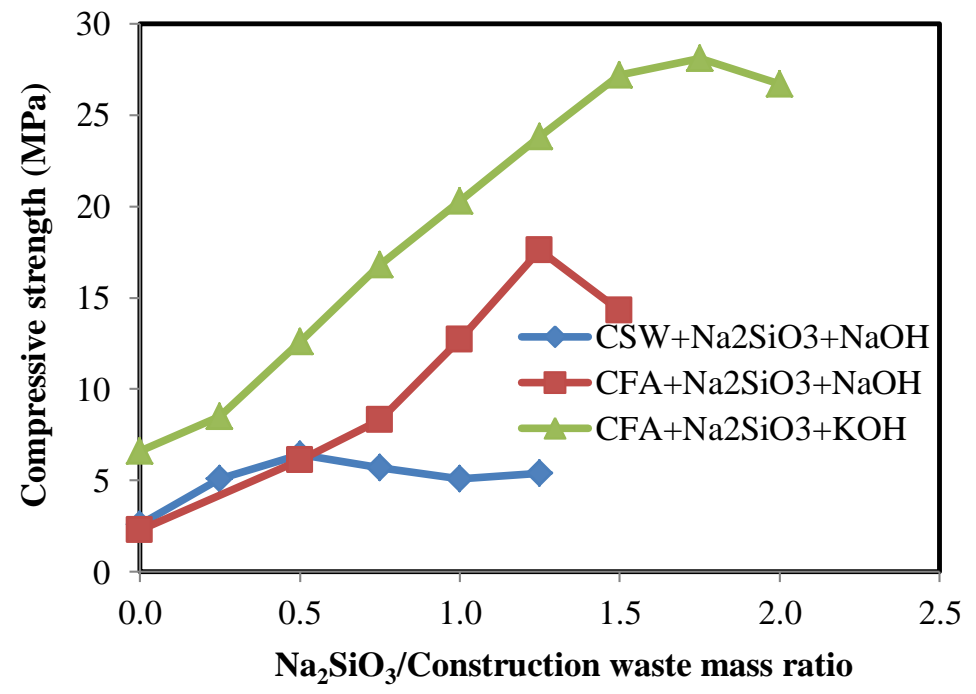

Figure 3: The change in compressive strength of geopolymer products with the variation of the mass ratio of $\mathrm{Na}_{2} \mathrm{SiO}_{3}$ : construction waste

The compressive strength of geopolymer obtained from CFA waste (treated with $\mathrm{KOH}$ ) was found increasing and attained the highest strength $(28.1 \mathrm{MPa})$ with 1.75 mass ratio of $\mathrm{Na}_{2} \mathrm{SiO}_{3}$ : CFA. In cases of CFA (treated with $\mathrm{NaOH}$ ) and $\mathrm{CSW}$ (treated with $\mathrm{NaOH}$ ) the highest strengths were 17.6 and $6.1 \mathrm{MPa}$ with 1.25 and 0.5 mass ratios of $\mathrm{Na}_{2} \mathrm{SiO}_{3}$ : CFA and CSW respectively. With further increase the amount of sodium silicate, the compressive strengths of geopolymeric products were decreased.

The amount of the addition of sodium silicate plays a significant role on the final crushing strength of the geopolymer products. Sodium silicate solution contains self-polymerizing species (monomer, dimer 
and larger oligomer containing $\mathrm{Si}-\mathrm{O}-\mathrm{Si}$ chain) which influence soluble alumino-silicate units to polymerize ${ }^{3,12}$. After certain level of the addition of sodium silicate the further increase of sodium silicate has adverse impact over the strength of the geopolymeric product. This is expected to be due to excess silicate hinders water evaporation and structure formation ${ }^{13}$. Further increase of silicates concentration decreases the rate of geopolymerization reaction and the solidification of the paste takes prior to geopolymerization $^{14,15}$.

\section{Compressive strength and curing time}

The curing time of the geopolymer products were varied from 5 to 28 days at the temperature of $40^{\circ} \mathrm{C}$. The samples were removed from the oven after the required time period and cut into the desired size. These samples were polished in water papers to make the surface smooth. The compressive strength of each sample was measured. The compressive strength was found increasing with increasing curing time and compressive strength of $41.9 \mathrm{MPa}$ was achieved with 28 days of curing time when treated with sodium silicate and $\mathrm{KOH}$. The plot of compressive strength as a function of curing time is shown in Fig. 4.

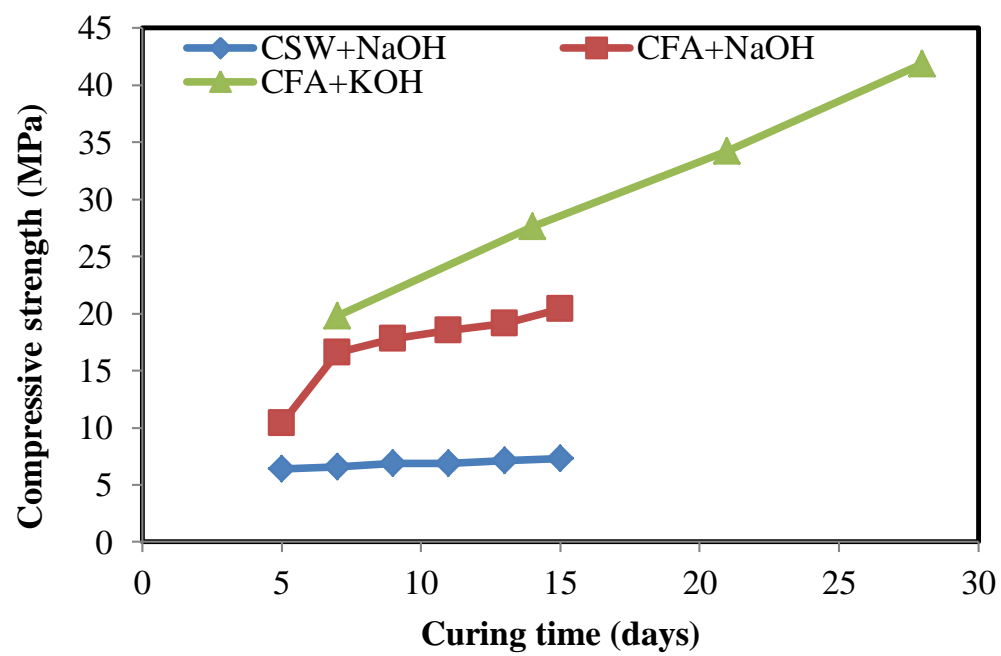

Figure 4: Change of compressive strength of geopolymer product with curing time

In geopolymers, the curing temperature and the curing time play significant roles not only as accelerators of chemical reaction, but also determine the extent of that reaction ${ }^{16,17}$. This is because at low temperature condensation of geopolymer precursors and evaporation of the water molecules take place simultaneously preventing the formation of voids and cracks inside the material thus increasing the compressive strength $^{18}$. This suggests that curing for longer time period at low temperature is preferable for the synthesis of geopolymer of higher compressive strength.

\section{Conclusions}

The geopolymers were synthesized from coal fly ash and cement-sand-waste by varying concentration of alkali, amount of $\mathrm{Na}_{2} \mathrm{SiO}_{3}$ and curing time and following conclusions were made from the present study: 
1. The compressive strength was found initially increasing and then decreasing with increasing alkali concentration.

2. With increasing the amount of sodium silicate, the compressive strength increased initially and then decreased.

3. The maximum compressive strength of $41.9 \mathrm{MPa}$ was achieved with 1.75 mass ratio of $\mathrm{Na}_{2} \mathrm{SiO}_{3}$ to CFA and $7 \mathrm{M} \mathrm{KOH}$ solution with 28 days curing time.

4. The compressive strength was found increasing with increasing curing time suggesting that curing for longer period of time at low temperature is preferable for the synthesis of geopolymer of higher compressive strength.

\section{Acknowledgements}

The authors are thankful to Nepal Academy of Science and Technology (NAST) for offering the project on geopolymer synthesis and helping to measure the compressive strength of few samples. We would like to acknowledge Associate Prof. Dr. Lalu Prasad Paudel, Head of Central Department of Geology, Tribhuvan University, Kirtipur, Kathmandu for his valuable help in X-Ray diffraction measurement of samples. We are thankful to Mr. Rajendra R. Pant of Central Material Testing Laboratory, Institute of Engineering Pulchowk Campus, Tribhuvan University, Kathmandu for helping to measure the compressive strength of the synthesized geopolymers.

\section{References}

1. K. Komnitsas and D. Zaharaki, Miner. Eng., 2007, 20, 1261.

2. H. Mingyu, Z. Xiaomin and L. Fumei, Cem. Concr. Comp., 2009, 31, 726.

3. H. Wang, H. Li. F. Yan, Colloids Surf. A: Physicochem. Eng. Asp., 2005, 268, 1.

4. P. Duxson, S. W. Mallicoat, G. C. Luckey, W. M. Kriven, J. S. J. Van deventer, Colloids Surf. A: Physicochem. Eng. Asp., 2007, 292, 8.

5. Z. Yunsheng, S. Wei, C. Qianli, C. Lin, J. Hazard. Mater., 2007, 143, 206.

6. E. Alverez-Ayuso, X. Querol, F. Plana, A. Alastuey, N. Moreno, M. Izquierdo, O. Font, T. Moreno, S. Diez, E. Vazquez, M. Barra, J. Hazard. Mater., 2008, 154, 175.

7. J. Temuujin, A. V. Riessen and R. Williams, J. Hazard. Mater., 2009, 167, 82.

8. A. Sathonsaowaphak, P. Chindaprasirt and K. Pimraksa, J. Hazard. Mater., 2009, 168, 44.

9. V.K. Jha and S. Hayashi, Science and Technical Reports of Faculty of Engineering and Resource Science, Akita University, 2009, 30, 35.

10. P.S. Singh, T. Bastow and M. Trigg, J. Mater. Sci., 2005, 40, 3951.

11. V.F.F. Barbosa, K.J.D. MacKenzie and C. Thaumaturgo, Proc. 2nd Int'l Conf. Geopolymer'99, Saint Qunentin, France, 1999, 65.

12. J.P. Hos, P.G. McCormick and L.T. Byrne, J. Mater. Sci., 2002, 37, 2311.

13. T.W. Chang and J.P. Chiu, Miner. Eng., 2003, 16, 205.

14. J.L. Provis and J.S.J. Van Deventer, J. Mater. Sci., 2007, 42, 2974.

15. J.L. Provis and J. S. J. Van Deventer, Chem. Eng. Sci., 2007, 62, 2309.

16. J. Davidovits, 1st Int'l Conf. on Alkaline Cements and Concretes at Kiev State Technical University, Ukraine, 1994, 131.

17. J. Davidovits, Chemistry of Geopolymeric Systems, Terminology, 1999, 9.

18. D.S. Perera, O. Uchida, E.R. Vance and K.S. Finnie, J. Mater. Sci., 2007, 42, 3099. 